\title{
EL CONVENTO DE SAN FRANCISCO DE MÉXICO
}

\section{Por Mariano Monterrosa Prado}

El 19 de septiembre de 1856, Vicente Pagaza mayor del Cuerpo Militar de Nacionales "Independencia", acompañado de los capitanes Valdés y Salazar, que tenían su cuartel en un ala del Convento de San Francisco, descubrieron en el atrio del mismo a un grupo de personas que supusieron tramaban una conspiración. Los sospechosos se refugiaron en el interior del convento y fueron aprehendidos en la celda del padre superior, llamado Magna Grecia. ${ }^{ \pm}$A consecuencia de esta real o supuesta conspiración, el 16 de septiembre del mismo año el presidente Comonfort publicó un decreto en que disponía que en el término de quince días, se abriera la calle llamada Callejón de Dolores, hasta comunicar con la de San Juan de Letrán, la cual se llamaría de la Independencia. Este decreto suprimía también el convento de franciscanos en la ciudad de México, por lo cual se procedió a demoler la enfermería, la cocina, varias celdas y parte de la huerta del convento. ${ }^{2}$

EI 19 de febrero de 1857 se concedió permiso a los franciscanos de volver a su convento, ocupando la parte que no había sido demolida, es decir, del lado de la iglesia mayor, ${ }^{3}$ donde permanecieron hasta el día 28 de diciembre de 1860 , a consecuencia de la publicación de las Leyes de Reforma, que suprimian las órdenes monásticas. Al año siguiente el convento fue fraccionado en nueve lotes para facilitar su venta. ${ }^{4}$

En 1861, se abrió la calle de Gante y se inició la demolición de varias capillas. El templo fue ocupado como caballerizas y bodegas del Circo Chiarini, pasando después al culto protestante. ${ }^{5}$

Las dependencias que cerraban el atrio, eran la habitación y el jardín del capellán de Aranzazú, abierta la calle de Gante, la capilla de Aranzazú por un tiempo sirvió de bodega y cobrería y finalmente se levantó sobre ella, el templo actual de San Felipe, la capilla de la Tercera

1 García Cubas, Antonio, El libro de mis recuerdos, 6 edición. Editorial Patria, S. A. México, 1969, p. 11.

2 Rivera Cambas, Manuel, México pintoresco, artistico y monumental. Editora Nacional, México, 1967 (colección Obras Famosas Ilustradas), t. 1, p. 224.

3 García Cubas, Antonio, op. cit., p. 117.

4 Ibidem, p. 119.

6 E. Rosell, Lauro, Iglesias y conventos coloniales de México, $2^{\text {a }}$ ed. Editoria] Patria, S. A. México, 1961, p. 178. 
Orden, en cuyo terreno se levantó una casa particular y el actual Hotel Guardiola. Entre estos dos templos, se abría el atrio con su portada que daba a la calle de San Francisco (hoy Francisco I. Madero) y en la esquina se encontraba la celda del capellán y las habitaciones del padre provincial. Por la calle de San Juan de Letrán, estaba la Capilla de los Dolores, pequeña y magnífica, que también era llamada de la Segunda Estación y según Alfonso Toro correspondia a la Tercera; ${ }^{\circ}$ inmediatamente estaba la otra portada que daba acceso al atrio por la mencionada calle. En seguida estaba la Capilla del Señor de Burgos, sustituida por la casa que llevó el número seis de San Juan de Letrán y que ocupó parte del atrio y su muro posterior quedó adosado a la fachada del templo grande. Junto estaba la celda del capellán del templo y, finalmente, el cuartel, parte del cual fue demolido al abrirse la calle de la Independencia, 7 al descubrirse la conspiración.

Los nuevos edificios que se levantaron sobre los terrenos del atrio y las capillas, acabaron con la fisonomía del famoso convento franciscano y ahogaron de tal manera lo poco que habia hasta el punto que el templo, utiliza hoy la portada lateral como acceso. La fachada principal dio tema a los historiadores del arte en México, para discutir si todavía se conservaba o si bien había sido destruida en el siglo pasado. El problema quedó sin solución, ya que níngún cronista de la época informa lo que ocurrió con la portada.

AI iniciarse las obras de demolición del edificio, a principios del año actual, renació la esperanza de que la portada se hubiera salvado.

En los primeros trabajos apareció un muro, que el arquitecto Javier Villalobos identificó como parte de la fachada de la Capilla del Señor de Burgos (figura 1), la cual daba al atrio; poco después se descubrió un relieve, aunque mutilado, que representa a Cristo en la segunda calda del Viacrucis, es decir de la Séptima Estación (figura 2). Ya hemos dicho que existía una pequeña capilla llamada De los Dolores, conocida también como de la Segunda Estación, pero no hay ninguna noticia que diga que en ella hubiera un relieve como el recién aparecido. Por el contrario, Betancourt habla de "Lienzos de la Pasión"; son muchas las litografías que muestran el Convento de San Francisco, pero no hay una sola en que aparezcan las portadas de las capillas fronteras

6 Toro, Alfonso, La cantiga de las piedras. Editorial Patria, S. A. México, 1961,

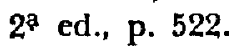

7 La ubicación puede verse en el plano de Garcia Cubas, en la obra citada, pp. 76,77 y 78 . 
DOI: http://dx.doi.org/10.22201/iie.18703062e.1976.46.1049

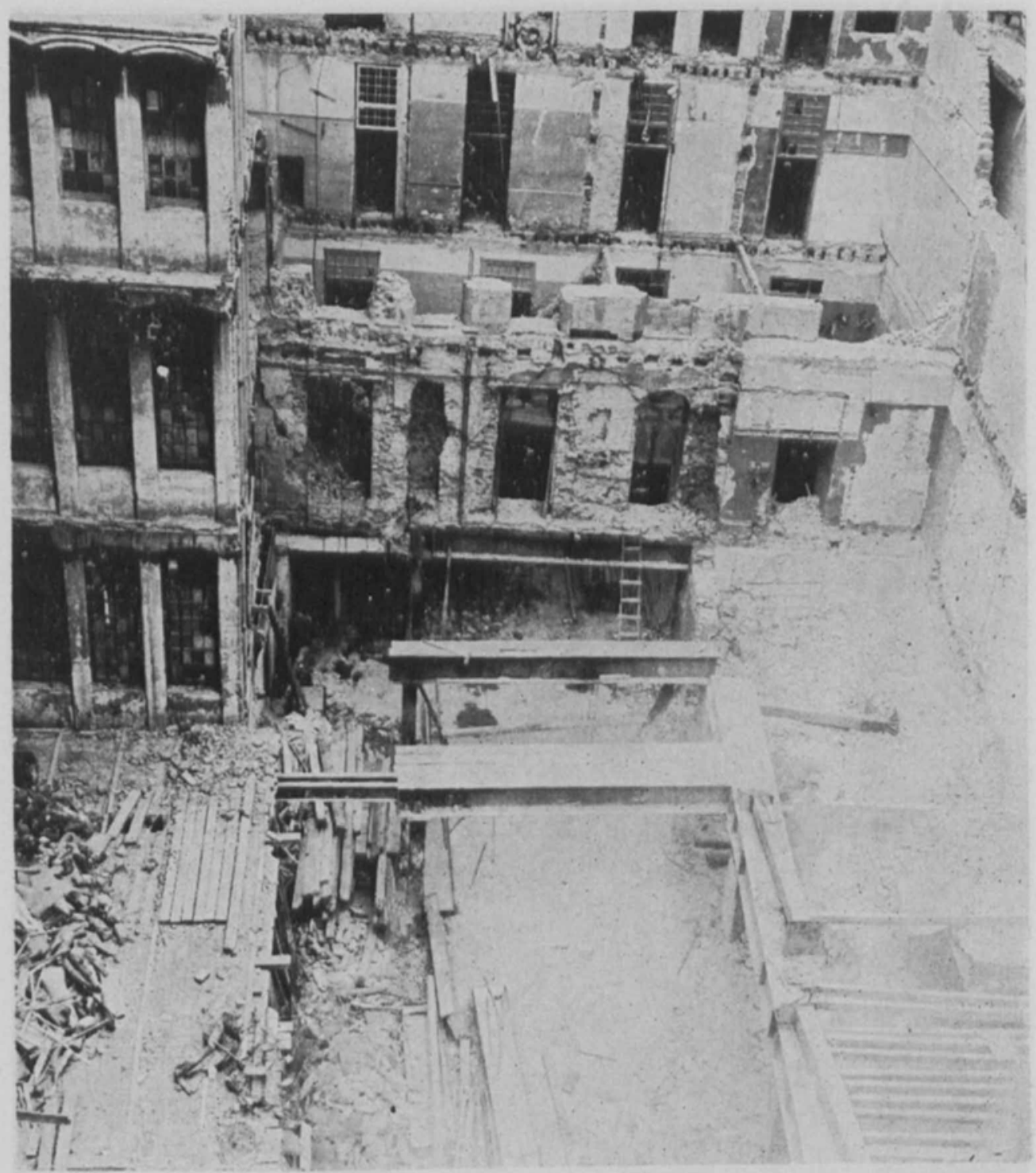

Figura 1. Ruinas de la Capilla del Señor de Burgos. 
DOI: http://dx.doi.org/10.22201/iie.18703062e.1976.46.1049

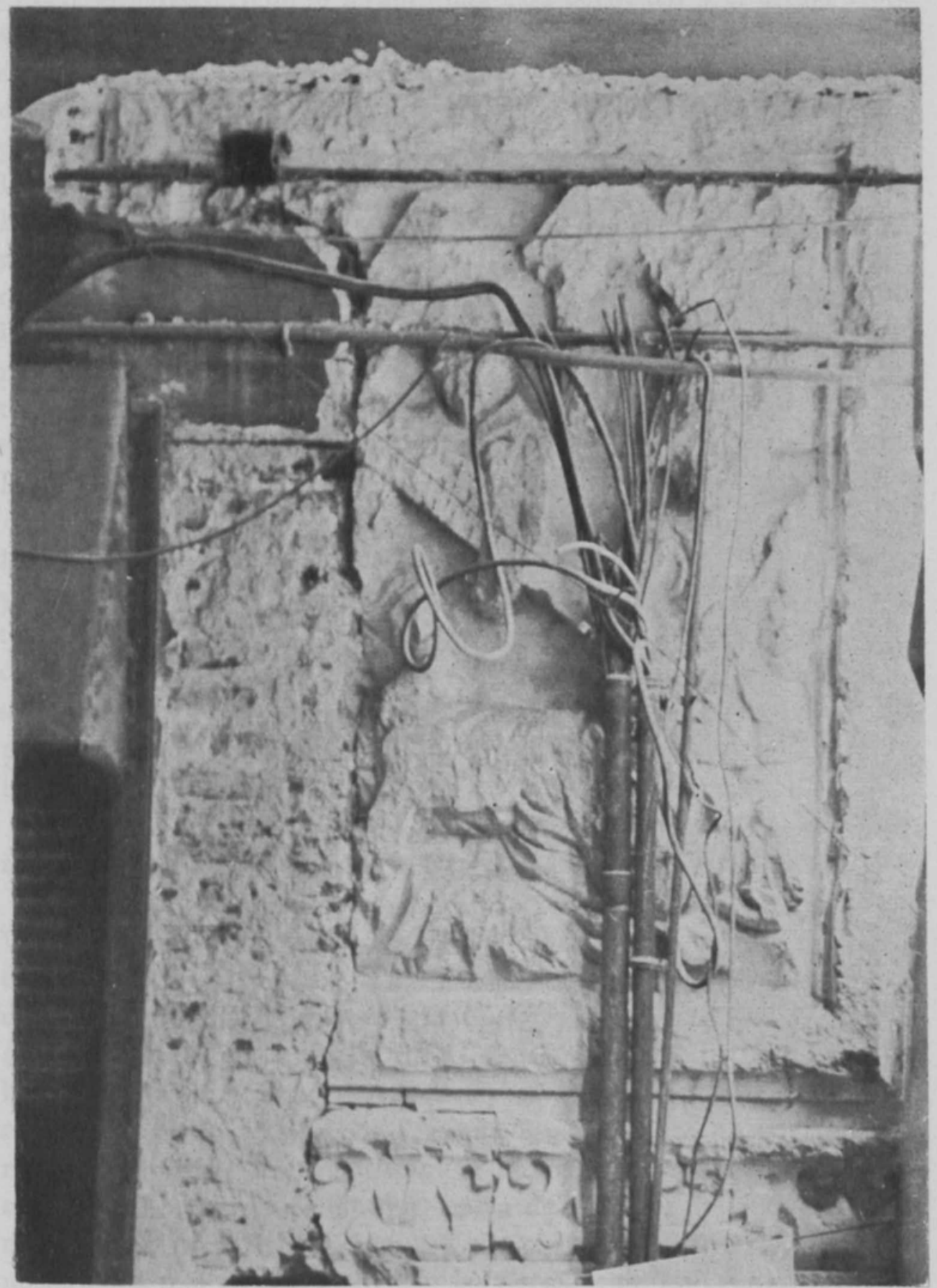

Figura 2. La Séptima Estación del Viacrucis. 
DOI: http://dx.doi.org/10.22201/iie.18703062e.1976.46.1049

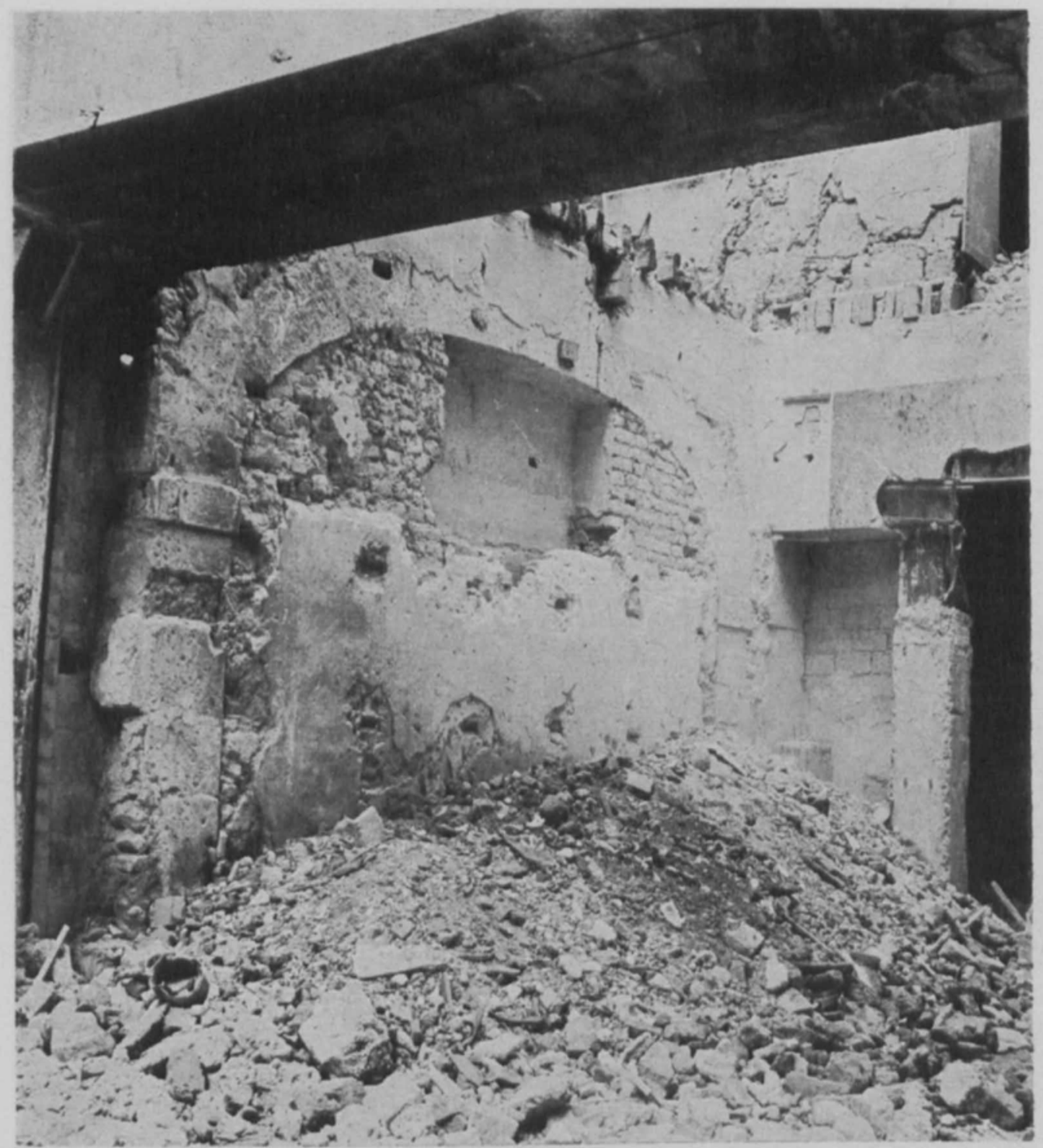

Figura 3. Ruinas de la Capilla del Señor de Burgos. 
DOI: http://dx.doi.org/10.22201/iie.18703062e.1976.46.1049

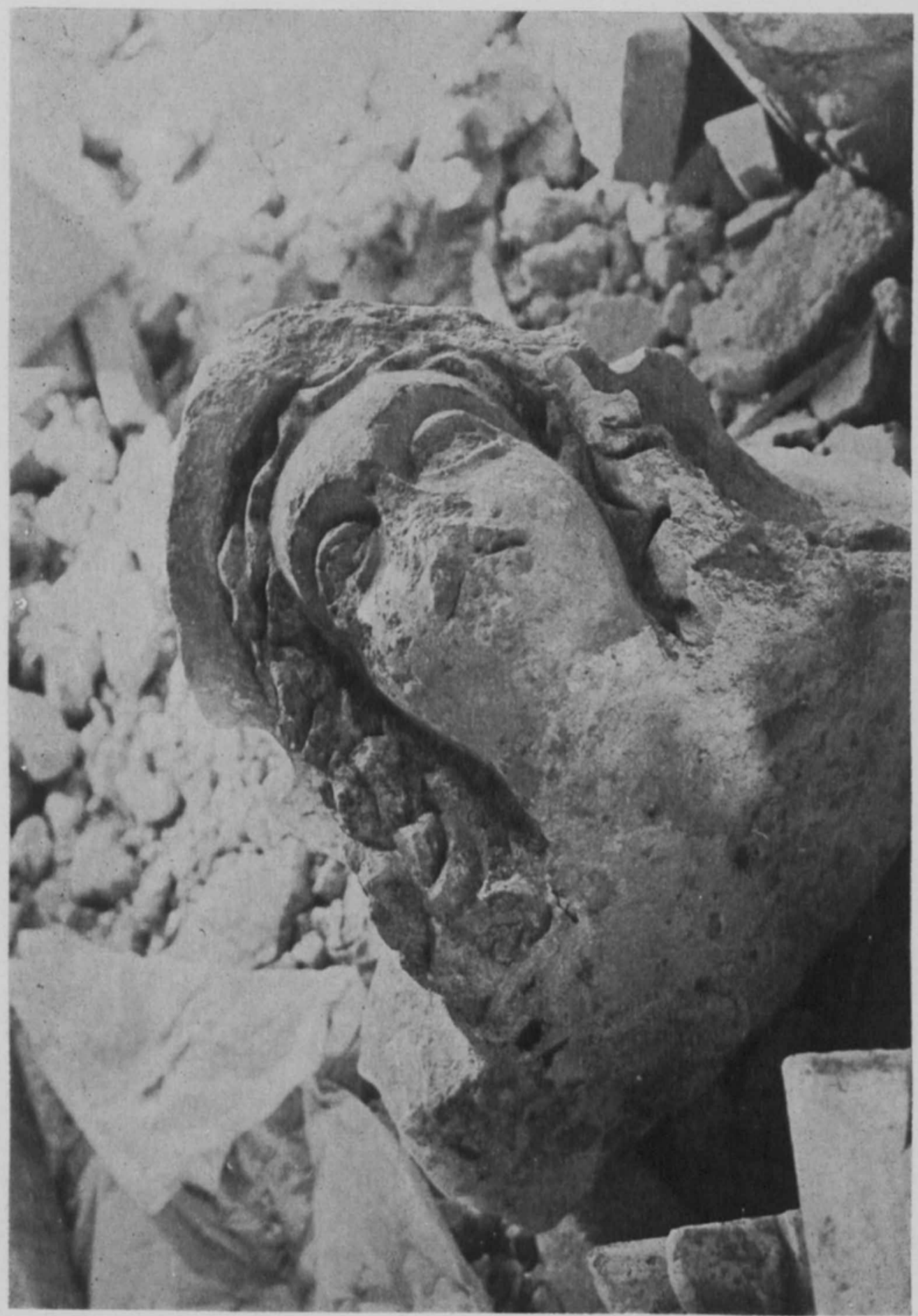

Figura 4. Cabeza de un ángel. Escultura en piedra. 
DOI: http://dx.doi.org/10.22201/iie.18703062e.1976.46.1049

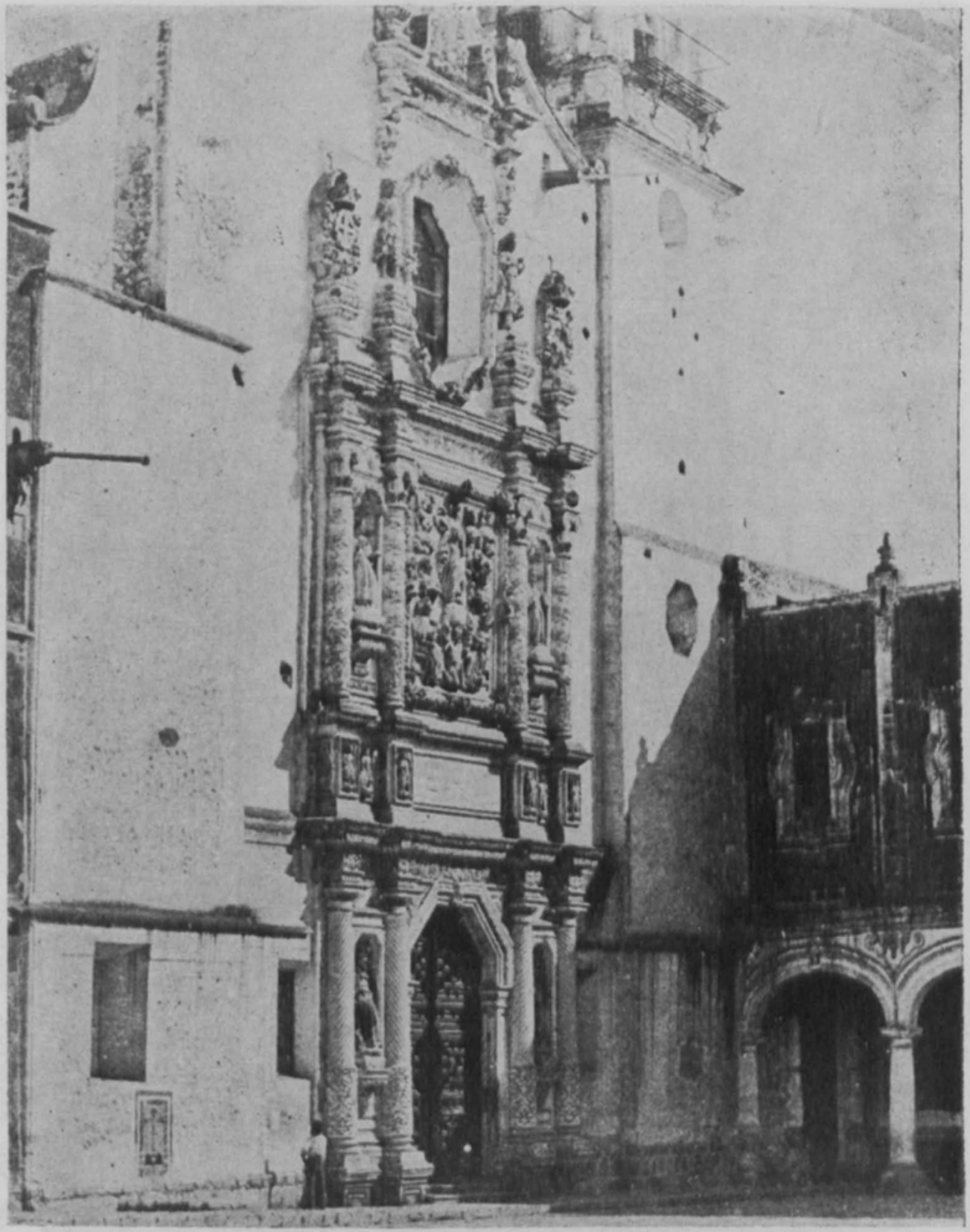

Figura 5. Iglesia de San Francisco. Fachada principal. Fotografía antigua. 
DOI: http://dx.doi.org/10.22201/iie.18703062e.1976.46.1049

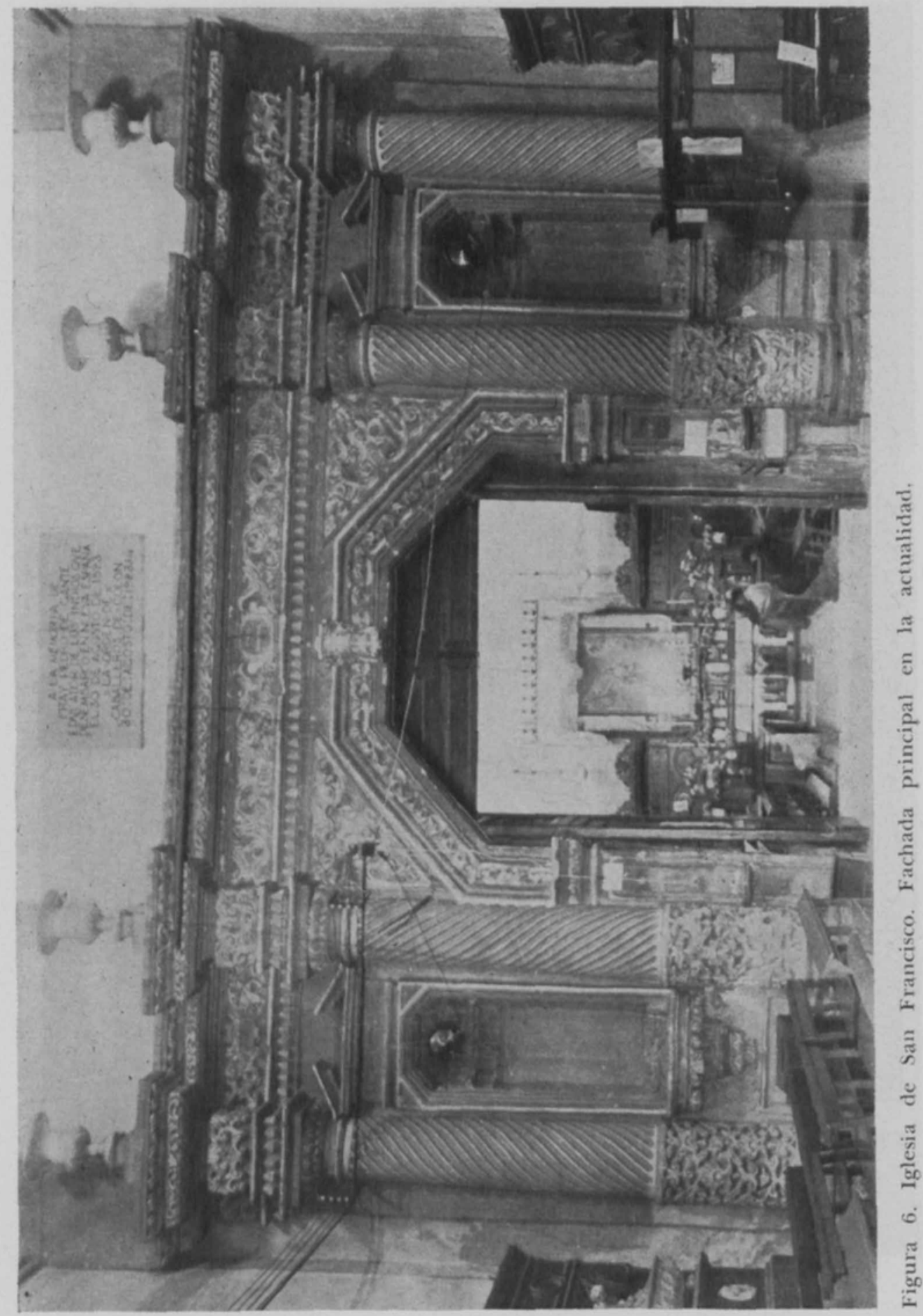


DOI: http://dx.doi.org/10.22201/iie.18703062e.1976.46.1049

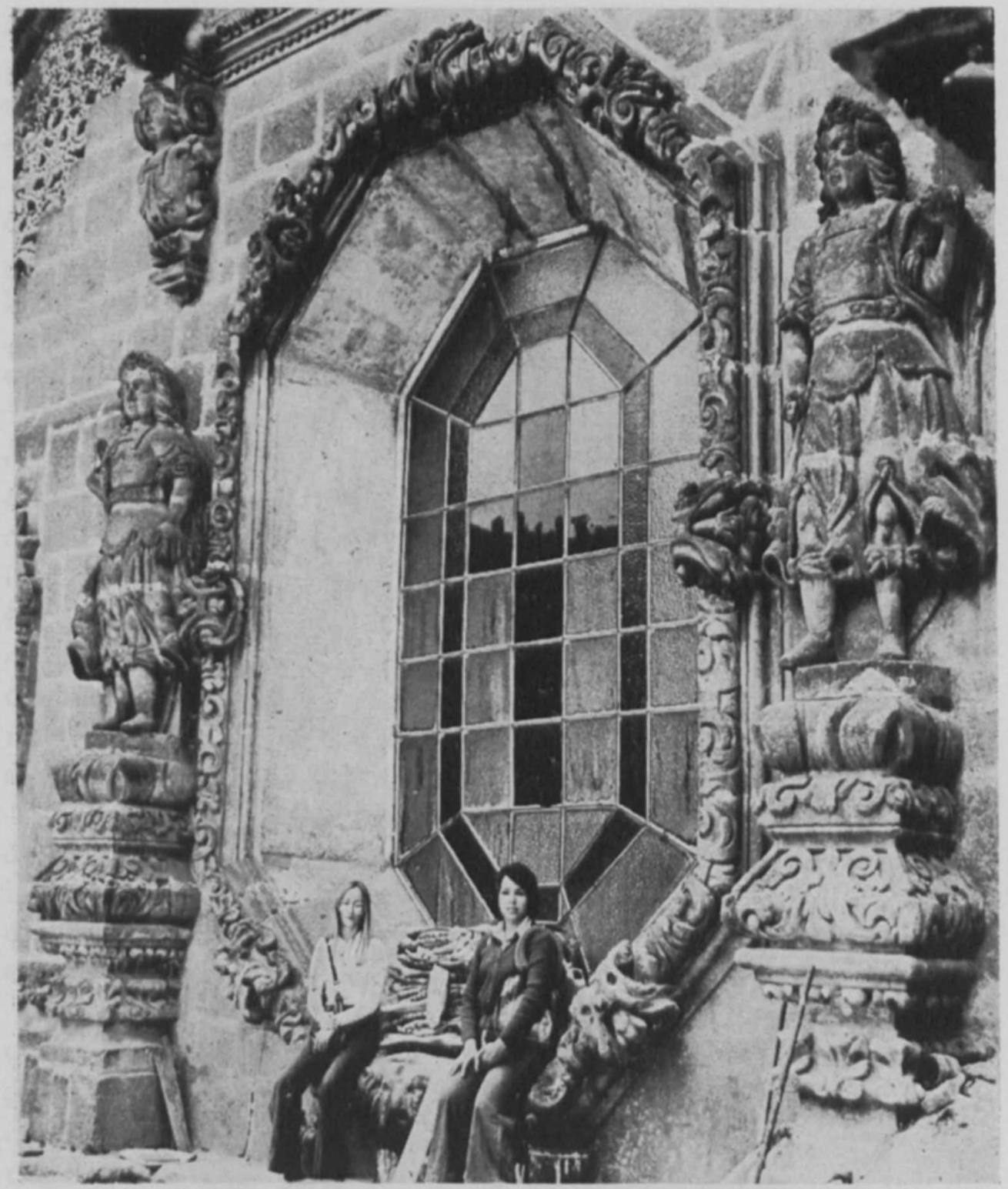

Figura 7. Iglesia de San Francisco. Ventana del coro. 


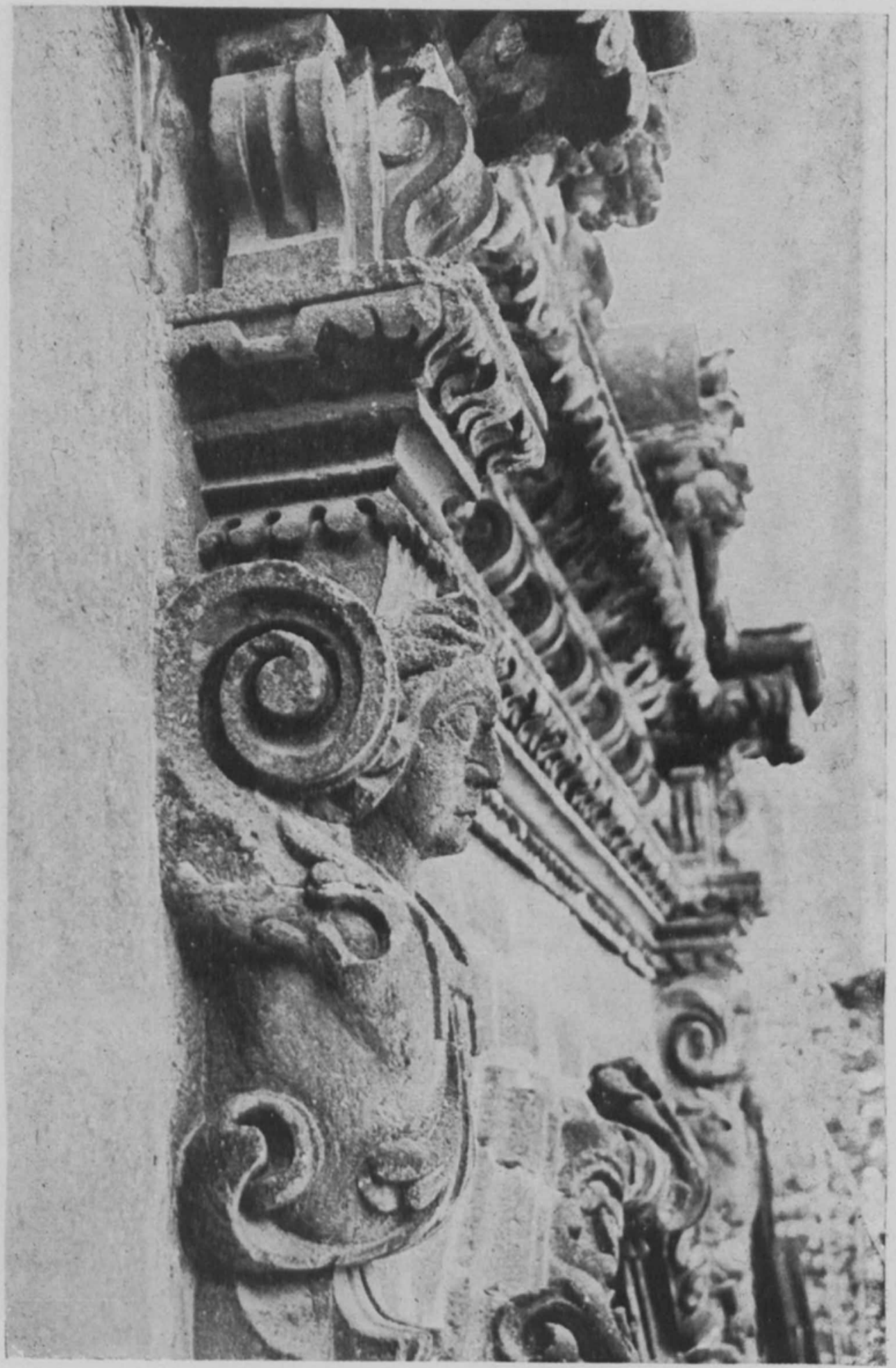

Figura 8. Iglesia de San Francisco. Remate de la fachada principal. 
a la fachada del templo conventual. Por ello pensamos primero, que para romper la monotonía de los muros, éstos se habían decorado con un Viacrucis; pero si este relieve representa la Séptima Estación, no quedaba lugar para las otras siete, dado su tamaño.

Se puede calcular que el relieve tenía dos metros de ancho; en él está representado Cristo en el momento de la caída y al ser flagelado por un soldado romano y a Simón el Cirineo quien le ayuda a levantar la cruz. En el lado derecho, se ven dos símbolos pasionarios, la espada de San Pedro con la oreja de Malco y más arriba las trece monedas. Quedan restos de pintura que representan guías vegetales.

Aparecieron además, los dos muros que dividían la Capilla del Señor de Burgos en tres secciones (figura 3) lo cual coincide de manera exacta con el plano de García Cubas y confirma la idea de que su descripción se apega a la realidad. Estos vestigios confirman también lo dicho por García Cubas, de que gran parte, del destruido convento, fue aprovechado para levantar nuevas construcciones. Al continuar las obras de demolición, apareció parte de la fachada del templo, pero desgraciadamente la portada ya no existe. Entre lo que resta se ve un roleo, el cual correspondió al cerramiento de la fachada; también subsisten restos del tezontle del ábside de la capilla de Balvanera.

El arquitecto Javier Villalobos, como representante de la Dirección de Monumentos Históricos, pidió se practicaran unas calas; en la que se hizo en la ventana del coro, apareció la cabeza de un ángel, de los que ornaban el remate (figura 4), lo cual quiere decir que los elementos escultóricos que componían la portada, fueron empleados como relleno.

Francisco de la Maza, publicó una fotografía estereoscópica ${ }^{\ominus}$ en la que se ve la fachada principal de la iglesia de San Francisco; esta fotografía es de gran valor para la historia del arte, porque si bien es cierto que existen varias litografías que la muestran, ninguna tiene la claridad y nitidez que la fotografía; gracias a ella nos enteramos que la portada lateral es idéntica a la principal, caso único en el arte virreinal, ya que lo común fue que la portada lateral se hiciera con un diseño diferente.

No sabemos por qué esta portada lateral no es mencionada por los

8 De Betancourt, fray Agustín, Teatro Mexicano. Descripción breve de los sucesos ejemplares, históricos y religiosos del Nuevo Mundo de las Indias. Editorial Porrúa, S. A. México, 1971, t. III, p. 40.

- De la Maza, Francisco, "La Portada de San Francisco", Boletin INAH, núm. 26, diciembre 1966, pp. 6-9. 
cronistas. Hoy funciona como portada interior, pues cuando se edificaron las capillas de La Purisima, hoy desaparecida, y la de Balvanera, quedó tapada, además destruyeron el relieve al levantar las bóvedas y las cúpulas. Sin embargo, atrás de éstas se encuentra un remate idéntico al de la portada principal; los remates laterales fueron raspados, seguramente en la época en la que se hizo lo mismo con la portada de la capilla de Balvanera, cuando el templo de San Francisco perteneció a la iglesia protestante (figuras 7 y 8 ). 